\title{
Effect of viscous dampers on yielding mechanisms of RC structures during earthquake
}

\begin{abstract}
The yielding mechanisms of reinforced concrete (RC) structures are the main cause of the collapse of RC buildings during earthquake excitation. Nowadays, the application of earthquake energy dissipation devices, such as viscous dampers (VDs), is being widely considered to protect RC structures which are designed to withstand severe seismic loads. However, the effect of VDs on the formation of plastic hinges and the yielding criteria of RC members has not been investigated extensively, due to the lack of an analytical model and a numerical means to evaluate the seismic response of structures. Therefore, this paper offers a comprehensive investigation of how damper devices influence the yielding mechanisms of RC buildings subjected to seismic excitation. For this purpose, adapting the Newmark method, a finite element algorithm was developed for the nonlinear dynamic analysis of reinforced concrete buildings equipped with VDs that are subjected to earthquake. A special finite element computer program was codified based on the developed algorithm. Finally, a parametric study was conducted for a three-story RC building equipped with supplementary VD devices, performing a nonlinear analysis in order to evaluate its effect on seismic damage and on the response of the structure. The results of this study showed that implementing VDs substantially changes the mechanism and formation of plastic hinges in RC buildings.
\end{abstract}

Keyword: Earthquake; Reinforce concrete; Viscous damper; Seismic damage; Yield surface; Finite element 